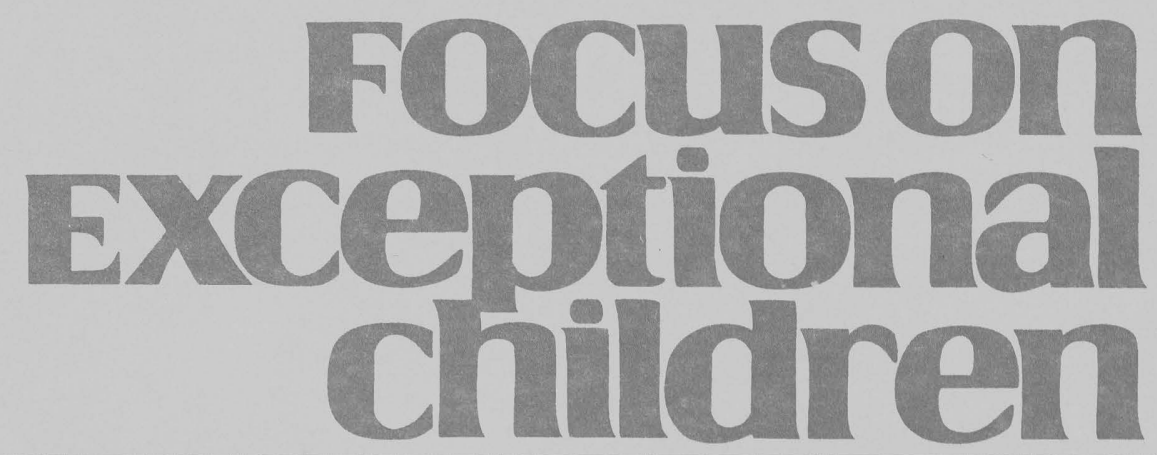

\title{
Positive Behavior Supports in Exclusionary Schools: A Practical Approach Based on What We Know
}

\author{
Joseph C. Gagnon, Sarah B. Rockwell, and Terrance M. Scott
}

Policy makers, community members, parents, and school administrators all recognize that the safety of our public schools is of the utmost importance (Barnoski, 2001; Snell, 2005). Highly publicized incidents of shootings at our nation's schools have raised public awareness of the need for safe schools and led to an outcry for reform (Leone, Mayer, Malmgren, \& Meisel, 2000). Although incidents of extreme violence at schools should not be ignored, they do not accurately represent the degree of safety in U.S. schools. In reality, incidents of violence at schools have steadily decreased over the past 15 years, few schools are considered to be persistently dangerous under federal guidelines, and for many students schools are significantly safer than the neighborhoods in which they live (Leone et al.; Snell)

Despite the increasing safety of public schools, disruptive behavior and school violence are still pressing issues. The Juvenile Offenders and Victims: National Report (Snyder \& Sickmund, 2006) describes continuing concerns with violence in schools. For instance, alarming percentages of students reported carrying weapons $(6.1 \%)$ or being threatened with a weapon (9.2\%) at school. Less severe forms of school violence are also problematic. For example, in a survey conducted in Washington State, $78 \%$ of elementary school teachers, $81 \%$ of middle school teachers, and $66 \%$ of high school teachers indicated that decreasing disruptive behavior was one of the top three priorities at their schools (Barnoski, 2001). Moreover, disruptive behaviors were cited as having a significantly negative impact on students' ability to learn. Low-severity violent behaviors may include classroom disruptions, noncompliance, teasing and bullying, theft, property damage, and fighting. Of these, bullying is the most prevalent (Whitted \& Dupper, 2005). According to Bowman (2001), 30\% of students in grades 6 through 10 reported bullying others, being bullied, or both. According to Snell (2005), 29\% of schools report bullying to be a serious problem. Also, approximately one third of students reported being involved in fights or having property stolen or vandalized while at school (Snyder \& Sickmund, 2006). These disruptive behaviors negatively affect student learning (Barnoski).

To address the harmful impact of problem behaviors, national legislation has emphasized the importance of school safety and behavioral interventions. The No Child Left

\footnotetext{
Joseph C. Gagnon is an Assistant Professor and Sarah B. Rockwell, M.A., is a doctoral student in the Department of Special Education at the University of Florida. Terrance M. Scott is Professor and Director of the Special Education Program at the University of Louisville.
} 
Behind Act (NCLB, 2002) aims at ensuring the adequate progress of all students by holding schools accountable for factors affecting student learning. NCLB (see $§ .4115,4116$ ) requires schools to report information on school safety and to implement procedures to improve school safety as part of these accountability procedures. Unacceptable information on school safety for three consecutive years results in that school being labeled as persistently dangerous. Students attending persistently dangerous schools may choose a different school (NCLB, see $\S 9532$ ). This provision for school choice indicates a recognition that students who attend unsafe schools are less likely to succeed than are students who attend safe schools.

In addition to NCLB (2002), the Individuals with Disabilities Education Improvement Act (IDEIA, 2004) contains provisions that specifically support students with identified disabilities. IDEIA emphasizes addressing the behavioral difficulties of students with disabilities through positive behavior interventions and supports. The provisions

\section{Focuson
Exceptional
children}

ISSN 0015-511X FOCUS ON EXCEPTIONAL CHILDREN (USPS 203-360) is published monthly except June, July, and August as a service to teachers, special educators, curriculum specialists, administrators, and those concerned with the special education of exceptional children. This publication is annotated and indexed by the ERIC Clearinghouse on Handicapped and Gifted Children for publication in the monthly Current Index to Journals in Education (CIJE) and the quarterly index, Exceptional Children Education Resources (ECER). The full text of Focus on Exceptional Children is also available in the electronic versions of the Education Index. It is also available in microfilm from Serials Acquisitions, National Archive Publishing Company, P.O. Box 998, Ann Arbor, MI 48106-0998. Subscription rates: individual, \$42 per year; institutions, \$56 per year. Copyright (C) 2008, Love Publishing Company. All rights reserved. Reproduction in whole or part without written permission is prohibited. Printed in the United States of America. Periodical postage is paid at Denver, Colorado. POSTMASTER: Send address changes to:

Love Publishing Company

Executive and Editorial Office P.O. Box 22353

Denver, Colorado 80222

Telephone (303) 221-7333

\section{EDITORIAL BOARD}

Lisa Dieker

University of Central Florida
Paula Maccini University of Maryland

Marleen Pugach

University of Wisconsin-Milwaukee

Carrie E. Watterson

Senior Editor
Stanley F. Love

Publisher regarding proactive behavior improvement plans in IDEIA regulations (2006, see 34 C.F.R.71. Sec. 300.324(a)(2)(i)) reflect an awareness that prevention systems, such as positive behavior supports (PBS), are a necessary and effective approach to managing the behaviors of students, including those with the greatest degree of difficulty (Putnam, Horner, \& Algozzine, 2006). Individualized behavior improvement plans that include positive behavior supports are an important component of student individual education plans (IEPs) (Sprague \& Horner, in press).

Unfortunately, the implementation of comprehensive, positive and proactive behavioral approaches in our public schools is rare (Snell, 2005). Instead, schools often rely on less effective reactive and exclusionary approaches that may impede student educational progress (Christle, Jolivette, \& Nelson, 2007; Liaupsin, Jolivette, \& Scott, 2005). The lack of a proactive plan is evident even in schools where the most serious offenses have occurred. For example, a review of publicly available information regarding school discipline procedures revealed that, of 25 schools in which highly publicized shootings had occurred since 1993, only two had put into place a comprehensive and proactive approach to managing student behavior following the incident. The remaining 23 schools had adopted reactive and punitive approaches.

Zero-tolerance policies that allow for little principal discretion, coupled with the inability of many public schools to address both student learning and emotional and behavioral concerns, have led to an increasing use of exclusionary school settings and what some have termed "the criminalization of behavior" (Leone, et al., 2000), whereby students are pushed out of the regular public school and into more restrictive settings. Specifically, exclusionary settings include day treatment and residential psychiatric facilities (DTR), juvenile corrections facility (JCF) schools for committed youth, and alternative schools.

Therapeutic day treatment programs focus on education and significantly emphasize student mental health, as well as social and clinical support to students' families (Armstrong, Grosser, \& Palma, 1992). The design of residential treatment facilities ensures the delivery of mental health treatment and education to youth with mental disorders as defined by the Diagnostic and Statistical Manual of Mental Disorders (DSM-IV) (American Psychiatric Association, 1994; Underwood, Talbott, Mosholder, \& Von Dresner, 2008). Variation in educational and psychiatric definitions often leads to confusion as to whether youth served in DTR schools are disabled or otherwise labeled. In fact, youth in DTR schools may or may not be identified with a special education classification of emotional disturbance (ED), a disability that affects their education (see IDEA, 2006). However, approximately 75,000 students in DTR facilities 
have a special education classification of ED (U.S. Department of Education (DOE), 2007).

Juvenile correctional facilities for detained youth are often locked facilities that house youth awaiting adjudication (i.e., the process by which a judge may or may not find a youth delinquent) (Sickmund, 2003). Juvenile correctional facilities for committed youth are secure care settings where youth are confined and educated after adjudication. In one year's time, delinquency results in commitment of roughly 144,000 youth to out-of-home placements (Snyder \& Sickmund, 2006).

An alternative school is "a public elementary/secondary school that addresses needs of students that typically cannot be met in regular school, provides nontraditional education, serves as an adjunct to a regular school, or falls outside the categories of regular, special education, or vocational education" (USDOE, 2002, p. 55). Information concerning the number of students attending alternative schools is limited. However, a study in which 20 states responded suggests that alternative schools serve at least one million students (Lehr, Moreau, Lange, \& Lanners, 2004).

One approach to student behavior that may be particularly useful in exclusionary settings is school-wide positive behavior supports (PBS). Walker, Cheney, Stage, and Blum (2005) describe PBS as a three-tiered model for intervening early with students to prevent school failure due to social or behavioral difficulties. The first tier aims at school-wide prevention by setting school-wide behavioral expectations, teaching these expectations to students, and reinforcing students for adhering to expectations. This tier prevents social and behavioral problems in approximately $80 \%$ of the student population. It also includes system-wide progress monitoring to determine the effectiveness of prevention procedures. Progress monitoring allows the PBS team to make changes to the prevention plan and identify students who may need more intense interventions.

Walker and colleagues (2005) also describe tiers two and three. At tier two are those students that have not responded favorably to school-wide prevention systems and are at risk of social or behavioral problems. This approximately $15 \%$ of the student population receives more intense interventions. Secondary group interventions include social skills groups, school counseling programs, peer mediation, increased monitoring and accountability, and other similar programs. The remaining chronic nonresponders are the approximately $5 \%$ who continue to struggle with social or behavioral failures and require tier three interventions. Interventions at this tier are individualized and necessarily more intense. These interventions and services may include functional behavioral assessment, development of a behavior improvement plan, or referral for special education or other services.
Increasingly, evidence shows that PBS is an effective approach to student behavior in regular public schools (Sugai \& Horner, 2005). Additionally, the few studies of exclusionary schools also reveal promising results (Jolivette, Kennedy, Pucket-Patterson, \& Houchins, 2008; Sidana, 2006). While the data on behavioral systems in exclusionary schools are extremely limited, the significant difficulties related to student behavior in these settings require a practical approach that relies on the available research. Our focus is to provide practical information to assist practitioners in implementing PBS in an exclusionary school.

However, as we describe in the sections that follow, youth in exclusionary settings face many difficulties. For example, among confined youth, as many as two thirds of males and three fourths of females may have a psychiatric disorder, and about half have a drug abuse problem (Teplin, Abram, McClelland, Dulcan, \& Mericle, 2002). Researchers have written extensively about the importance of providing a wide range of services to support the emotional and behavioral growth of students in exclusionary settings (see Nelson, Sprague, Jolivette, Smith, \& Tobin, in press). The importance of offering comprehensive services should be underscored: PBS should be combined with additional services, including such comprehensive approaches as multi-systemic therapy (see Burns, Schoenwald, Burchard, Faw, \& Santos, 2000; Gagnon \& Richards, 2008; Nelson et al., in press). A comprehensive review of these topics is beyond the scope of our current discussion. Rather, in the sections that follow, we look at how PBS, a multitiered, research- based approach to student behavior, has proven to be an appropriate and effective approach in both regular public schools and exclusionary settings.

\section{PBS IN PUBLIC SCHOOLS}

Currently, more than 6,000 schools in 37 states use PBS (Danielson, Cobb, Sanchez, \& Horner, 2007 as cited in Read, Quinn, \& Nelson, 2008), and the effectiveness of PBS in public schools has been the focus of a large body of research. This section describes common approaches to student behavior in public schools, the rationale for using PBS to manage student behavior, the steps involved in effectively implementing PBS, and ways to overcome barriers to implementing PBS. In later sections, we address exclusionary settings by discussing four main issues: unique attributes of the setting and students, common approaches to student behavior, and PBS research and implementation examples. Finally, we provide methods for overcoming barriers to implementation of PBS in exclusionary settings and resources for practitioners. 


\section{Common Approaches to Student Behavior in Public School Settings}

In the last 25 years, many schools have adopted more punitive approaches to violence prevention in public schools. These include use of metal detectors, video surveillance, searches, and zero-tolerance policies (Van Acker, 2007). With these approaches, infractions of school rules result in punishments that are intended to match the severity of the rule infraction. Schools frequently administer these punishments rigidly and without regard to the context of the rule infraction, especially when schools enact zero-tolerance policies. All 50 states have enacted zero-tolerance legislation that requires suspension or expulsion and provides for no administrator discretion in determining appropriate punishment for certain types of rule infractions (e.g., weapons, drugs, threats of violence) (Yell \& Rozanski, 2000). In some cases, schools refer students to law enforcement agencies following such rule infractions. Although these punitive approaches to managing student behavior are popular, they are actually ineffective at preventing or reducing violent and disruptive behavior and are associated with increased student dropout and incarceration (Noguera, 1995; Wald \& Losen, 2003; Yell \& Rozanski).

The ineffectiveness of negative and reactive methods of managing student behavior has led researchers to suggest alternative, less coercive approaches. Leone and colleagues (2000) advocate the use of a comprehensive system of school-wide support. They explain that such a system should include a primary level of school-wide prevention, small-group strategies for some students, and individualized services for a select group of students in need of intensive support. The PBS model exemplifies such a tiered approach to prevention of problem behaviors.

\section{PBS Implementation}

The Office of Special Education Programs (OSEP) National Technical Assistance Center on Positive Behavior Supports has published a blueprint that provides steps that schools can follow in adopting PBS (OSEP, 2004). These steps include (a) forming a PBS team to guide the process; (b) obtaining support and commitment from faculty, staff, and administration; (c) assessing the current school discipline climate to determine areas of strength and need; (d) creating and implementing an action plan for addressing needs related to school-wide discipline; and (e) developing a datacollection system to monitor progress and facilitate databased decision making. Examples of how various schools have implemented each of these steps are provided in the following section.

\section{Forming the PBS Team}

The PBS team should include a representative from each group of stakeholders within the school setting. OSEP (2004) suggests that this team include an administrator, teacher representatives from each grade level or subject area, members of the support staff, and parents. Schools create the PBS team in different ways. For instance, teams may be enthusiastic volunteers (Netzel \& Eber, 2003; Metzler, Biglan, Rusby, \& Sprague, 2001), nominees chosen by administrators, consultants, or researchers (Bohanon, et al., 2006; Turnbull et al., 2002; Oswald, Safran, \& Johanson, 2005), or peer-elected representatives (Scott, 2001).

Regardless of how the school forms the PBS team, it serves a critical role in driving implementation. In some cases, the PBS team may attend professional development activities and then disseminate information to the rest of the school staff (Netzel \& Eber, 2003). The PBS team is often responsible for developing school-wide behavioral expectations, plans for teaching those expectations, and plans for reinforcing appropriate behavior (Bohanon et al., 2006; Metzler et al., 2001; Netzel \& Eber; Oswald et al., 2005; Turnbull et al., 2002). Finally, the PBS team is instrumental in problem solving and making data-based decisions (Luiselli, Putnam, Handler, \& Feinberg, 2005; Metzler et al.; Scott, 2001).

\section{Obtaining Support and Commitment}

To be effective, the PBS system must function throughout the school day in all settings, a requirement that means all school personnel must be committed to the PBS process (Scott, 2001). Support and commitment can arise through professional development activities to ensure that school personnel fully understand PBS and its benefits before action planning begins (Luiselli et al., 2005; Metzler et al., 2001; Netzel \& Eber, 2003; Oswald et al., 2005; Scott). Another approach is to engage the entire staff in brainstorming activities related to setting priority behavioral expectations, planning teaching activities, and planning reinforcement activities (Oswald et al.; Scott; Turnbull et al., 2002). By ensuring that the PBS action plan is agreeable to the staff, schools increase the likelihood that the plan will be followed. Further, program implementation can be promoted via reinforcement of staff for helping to implement the action plan (Netzel \& Eber).

\section{Assessing the School Discipline Climate}

Before developing priorities for inclusion in the action plan, a school must determine common problem behaviors and contexts, existing procedures for encouraging appropriate behavior, and useful supports already present in the school (Netzel \& Eber, 2003). To identify existing discipline procedures and issues, schools have used several different assessment techniques. Formal assessment methods include the Effective Behavior Supports Survey (Oswald et al., 2005; Netzel \& Eber) and analysis of school discipline data 
such as office discipline referrals (ODRs) (Bohanon et al., 2006; Netzel \& Eber). Less formal assessment methods include brainstorming sessions (Scott, 2001), interviews with faculty and staff members (Bohanon et al.), and observations of student behavior in various school settings (Kartub, Taylor-Greene, March, \& Horner, 2000).

\section{Creating and Implementing the Action Plan}

After identifying common problem behaviors, the school can begin to develop the PBS action plan, which consists of several parts. The first step is to develop a short list of positively stated behavioral expectations, which focus on the behaviors students should engage in rather than on problem behaviors (Netzel \& Eber, 2003). These behavioral expectations may also serve as a means of developing a cohesive school culture (Turnbull et al., 2002).

The next step is to devise a plan for teaching behavioral expectations to students. This plan may include posting expectations throughout the school, providing assembly times to teach expectations and develop a positive school climate, or developing lesson plans that teachers can use to teach behavioral expectations (Bohanon et al., 2006). Instruction should focus on the contexts in which problem behaviors commonly occur to provide students with opportunities to discriminate and practice appropriate behavior (Turnbull et al., 2002). For instance, at one school where hallway behavior was a problem, students were given opportunities to role-play appropriate and inappropriate examples of hallway behavior (Oswald et al., 2005).

Teaching behavioral expectations ensures that students know how to behave appropriately, but it does not encourage them to do so. Therefore, the action plan must include strategies for encouraging appropriate behaviors (Turnbull et al., 2002). In many cases, simply changing the context in which problem behaviors commonly occur can encourage appropriate behavior (Oswald et al., 2005). For instance, Kartub and colleagues (2000) found that in one school, dimming the lights in the hallways during lunch served as a cue to encourage quiet transitions. In another school, adjusting the lunch schedule to reduce wait times encouraged appropriate behavior in the lunch line (Scott, 2001).

In addition to describing adjustments that make contexts more conducive to appropriate behavior, the action plan should set out methods for reinforcing students for engaging in appropriate behavior (Turnbull et al., 2002). One common technique for providing school-wide reinforcement is the token economy, in which students receive tickets or tokens for behaviors that exemplify school-wide expectations. Tokens or tickets are easy to administer and can be exchanged for a variety of back-up reinforcers (DuPaul, 2007). For instance, tickets have been used in periodic drawings for various prizes, exchanged for items purchased at a school store, and exchanged for privileges and activities such as the opportunity to participate in a school dance (Bohanon et al., 2006). Another common means of reinforcing appropriate behavior is through group contingencies, as when one school provided rewards to entire classrooms of students contingent on their table being clean at the end of lunch (Scott, 2001).

Encouraging and reinforcing appropriate behavior will not prevent all behavior problems. Certain classrooms, groups of students, or individual students may continue to demonstrate problem behaviors. To address this issue, the action plan should include clear consequences for rule infractions and provisions for tiers two and three services (Turnbull et al., 2002). Many of these more intense services may already be available. For instance, schools may already have group social skills programs, peer mentoring programs, or peer mediation programs. They may also have access to a behavior specialist, who can conduct functional behavioral assessments and develop and implement individual behavior plans. To the extent that schools do not have such services, they will need to develop them as part of the action plan. For instance, the team may need to plan for professional development in classroom management for struggling teachers (Luiselli et al., 2005).

\section{Developing a Data Collection System}

One benefit of PBS is that it is not static. Rather, PBS represents a problem-solving approach to developing effective behavior supports at varying levels of intensity. To facilitate problem solving, the school must collect data to enable the PBS team to evaluate the effectiveness of both the action plan and specific services for particular students (Turnbull et al., 2002).

Luiselli and colleagues (2005) describe an approach to data collection using office discipline referrals (ODR) and suspension information. ODR and suspension data can identify individual students who have received multiple behavioral infractions and thus may need more intense services. ODR and suspension data can also be used to track changes in the overall instances of behavioral problems or to identify spikes in problem behavior based on time or location. Using these data, the PBS team can identify additional contexts needing adjustments or behaviors requiring explicit instruction, or the team can consider ways of altering the action plan to provide more or less frequent reinforcement.

Bohanon and colleagues (2006) describe another approach to data collection for program evaluation. The School-Wide Evaluation Tool (SET) is a formal assessment instrument that allows the team to evaluate the extent to which a school is using critical components of PBS (Todd et al., 2003). This information allows the team to determine areas for action plan revision and creates a context for evaluating the effectiveness 
of PBS. Because the teaching domain of the SET and overall SET score must be at $80 \%$ for a school to realize the full benefits of PBS, poor outcomes may be due to inadequacy of PBS implementation rather than to flaws in the action plan (Bohanon et al.).

\section{Benefits of PBS Implementation}

The PBS model is supported by a growing body of research demonstrating its efficacy at reducing behavioral problems and improving student outcomes in public school settings. Research indicates a statistically significant interaction between student academic scores and office disciplinary referrals (McIntosh, Flannery, Sugai, Braun, \& Cochrane, 2008). Moreover, numerous studies of ODR and suspension data indicate that PBS is effective at reducing behavior problems (Kartub et al., 2000; Metzler, Biglan, Rusby, \& Sprague, 2001; Oswald et al., 2005; Scott, 2001; Turnbull et al., 2002). These studies show that PBS not only reduces the total number of behavioral problems, but also reduces the number of students with repeated behavioral infractions (i.e., those needing tier two or three services).

In addition to demonstrating a reduction in behavioral problems, Scott and Barrett (2004) examined the impact of reduced disciplinary problems on instructional time. They found that following PBS implementation, students experienced many more hours of instruction because less student time was spent in exclusionary punishment and less teacher time was spent addressing behavioral concerns. As a result, they hypothesized that PBS would have a positive impact on academic performance as well as on behavior.

Studies now indicate that PBS does in fact improve academic outcomes for students. For instance, in one school district implementing PBS along with a tiered system of reading interventions, behavioral and academic outcomes far exceeded expectations, which had assumed that approximately $20 \%$ of students would need tier two or three interventions (McIntosh, Chard, Boland, and Horner, 2006). In fact, in that school district, $97 \%$ of students were academically successful and $92 \%$ were behaviorally successful with tier one services only. In another study, a notable increase occurred in reading and math performance on a statewide assessment after PBS implementation in one school (Luiselli et al., 2005). Similarly, statistically significant gains occurred in reading and math performance among students at an urban middle school following PBS implementation (Lassen, Steele, \& Sailor, 2006).

In addition to research studies showing the efficacy of PBS, several publications are available to assist practitioners who would like to effectively implement PBS in a regular public school setting. We have included some of these useful resources in Figure 1.

\section{Resources}

\section{Books/Articles:}

Crone, D. A., \& Horner, R. H. (2003). Building positive behavior support systems in schools: Functional behavioral assessment. New York: Guilford Press.

Lohrman, S., Forman, S., Martin, S., \& Palmieri, M. (2008). Understanding school personnel's resistance to adopting schoolwide positive behavior support at the universal level of intervention, Journal of Positive Behavior Intervention OnlineFirst, Retrieved September 3, 2008, from http://jpbi.sagepub.com

Stormont, M., Lewis, T. J., Becknew, R. S., \& Johnson, N. W. (2008). Implementing positive behavior support systems in early childhood and elementary settings. Thousand Oaks, CA: Corwin Press.

Turnbull, A., Edmonson, H., Griggs, P., Wickham, D., Sailor, W., Freeman, R., et al. (2002). A blueprint for schoolwide positive behavior support: Implementation of three components. Exceptional Children, 68(3), 377-402.

\section{Organizations/Websites:}

National Technical Assistance Center on Positive Behavioral Interventions and Supports (PBIS), see http://www.pbis.org/main.htm

\section{FIGURE 1 Resources for implementing PBS in public schools}

\section{EXCLUSIONARY SCHOOL SETTINGS}

Separate educational systems serve many of our youth with the most severe emotional and behavioral problems. Logically, students in these schools would benefit most from a comprehensive behavioral plan that promotes positive prosocial behavior via PBS.

In the sections that follow, we focus on three types of exclusionary settings: (a) day treatment and residential, (b) juvenile corrections, and (c) alternative schools.

\section{Students in Day Treatment and Residential Psychiatric (DTR) Facilities}

Nationally, approximately 75,000 youth with ED are educated in DTR schools (USDOE, 2007). These schools have a unique student population whose characteristics may affect both the need for and use of PBS. For example, in DTR schools $90 \%$ of students are classified with a disability, in contrast to about $12 \%$ in regular U.S. schools (Gagnon, Van Loan, \& Barber, 2008; Stizek, Pittsonberger, Riordan, Lyter, \& Orlofsky, 2007). Moreover, in public schools only $11 \%$ of youth with disabilities have ED, compared to $70 \%-93 \%$ in DTR schools (Duncan, Forness, \& 
Hartsough, 1995; Gagnon, Van Loan, \& Barber; Wagner, Cameto, \& Guzman, 2003). The high percentage of youth with disabilities, particularly EBD, may require a greater emphasis on secondary and tertiary interventions than in a typical public school.

Student mental health concerns also compound the difficulties of addressing youth behavior in DTR facilities. In addition to the high percentage of students with disabilities in DTR, these youth frequently have comorbid special education classification and mental disorders, as classified by the DSM-IV (American Psychiatric Association, 1994; Jolivette et al., 2008). For example, one study reported that $46 \%$ of youth in a residential program had a substance abuse disorder (Leichtman, Leichtman, Barber, \& Neese, 2001). Additionally, $80 \%$ of youth in DTR have experienced some form of abuse (Hooper, Murphy, Devaney, \& Hultman, 2000).

Provision of appropriate services for youth in DTR will often require the collaboration of educators and other professionals because youth in DTR are more likely to be involved in juvenile corrections and in foster care (Gagnon \& Leone, 2006). Greenbaum and colleagues (1996) followed youth from DTR for seven years and noted that $43 \%$ were arrested at least once and 34\% were adjudicated. Youth in DTR are also more likely to participate in therapy. For example, Hooper and colleagues (2000) reported that $85 \%-91 \%$ of youth in DTR participated in individual therapy. Moreover, students in DTR are also more likely to require psychotropic pharmacology: $65 \%-90 \%$ of youth in DTR settings are provided psychotropic medication (Hooper et al.; Leichtman et al., 2001; Ryan, Reid, Gallagher, \& Ellis, 2008). The overlap among special education, psychiatry, therapy, probation and parole, and social services (i.e., the foster care system) requires a collaborative cross-agency approach to addressing maladaptive student behavior.

\section{Common Approaches to Student Behavior in DTR Schools}

Little research identifies common approaches to student behavior in DTR schools. However, in a study of teachers of youth with emotional handicaps or severe emotional disturbance (state classifications at the time of the study), $71 \%$ reported they were currently using a level system (Farrell, Smith, \& Brownell, 1998). A level system is defined as a

behavior management strategy that establishes a hierarchy of increasing expectations for behavioral improvement with increasing student reinforcement and decreasing behavioral structure. Typically, students advance through the sequence of four or five levels, each associated with higher expectations for academic performance and social behavior, as well as with greater student autonomy and access to more naturalistic reinforcers (Kerr \& Nelson, 2002, p. 189).
Level systems are commonly combined with a behavioral approach termed point or token systems (Mohr \& Pumariega, 2004). The use of points or tokens is

\begin{abstract}
based on operant conditioning techniques and uses behavioral modification within the therapeutic milieu. The model identifies behaviors of an individual that are maladaptive, sets behavioral goals, and then modifies target behaviors using positive reinforcement and other operant conditioning techniques (Underwood et al., 2008, pp. 223-224).
\end{abstract}

Combined point and level systems are a potentially effective approach to youth maladaptive behavior. However, experts have voiced concerns over the use of such systems in light of the key components of effective PBS. For example, critics have noted that token systems may result in the possible neglect of secondary and tertiary interventions and that psychiatric programs may be needed to supplement generic or universal treatment approaches with individualized treatment planning (Mohr \& Pumariega, 2004). In fact, researchers reported that students who did not respond to a point and level system improved their behavior when an individualized self-management program was added (Cavalier, Ferretti, \& Hodges, 1997). The shifting of level systems to a more punitive system also raises concerns. For example, professionals tend to rely on punishments (i.e., administering negative consequences designed to reduce behaviors) rather than withholding points or privileges for inappropriate behavior (Mohr and Pumariega). Although this concern may appear to be minor, the negative effects of a punishmentbased system are well documented (Small, Reynolds, O’Connor, \& Cooney, 2005).

Another concern with point and level systems is that the approach may not be based on a functional assessment of student behavior with individualization based upon the information collected (Mohr \& Pumariega, 2004). Particularly for youth in DTR settings, who have a host of difficult characteristics (e.g., history of abuse and neglect, lack of stable attachments, current psychiatric disorders), a thorough understanding of the context surrounding youth behavior is critical (VanderVan, 1995). For example, Farrell and colleagues (1998) reported that $80 \%$ of youth automatically began on the lowest level (i.e., fewest expectations and privileges) upon entry into the program, regardless of individual needs. Additionally, $72 \%$ of those using level systems provided a single universal system with no individualization. Only $20.5 \%$ made some accommodations and only $6.6 \%$ reported developing any separate systems for individual students. VanderVan also reported a lack of consideration for individual youth mental disorders and related issues. For example, the literature contains no discussion of necessary level system adaptations when doctors are trying new medication regimes. 
Research is scant on the effectiveness of point and level systems, whether in isolation or combined. One study reported that the use of level system data was effective as one of several predictors of future school performance (Nickerson, Brosof, \& Shapiro, 2004). In general, teachers have positive views concerning the level system and its effect on student behavior. Yet, teachers are less positive with regard to the system leading to greater increases in student participation in the general education environment or to students exiting special education (Farrell, Smith, \& Brownell, 1998).

Point and level systems do include methods that have proven effective. For example, the point system, in effect, provides reinforcement to students for specific behavior. Research identifies the use of contingent reinforcement as one of the most effective practices for changing student behavior (Lewis, Hudson, Richter, \& Johnson, 2004). However, two underlying assumptions of level systems do not have research support: (a) that combining techniques (e.g., token economies, positive reinforcement, shaping, fading, contingency contracts) is effective; and (b) that a hierarchical system effectively shapes behavior and promotes generalization, as behaviors are "controlled by naturally occurring reinforcers" (Smith \& Farrell, 1993, p. 258).

Currently, evidence is insufficient that point and level systems as a "package" are an effective approach to student problem behavior. Possibly DTR schools could use a point and level system as a component of PBS. However, as we noted in our discussion of PBS in public schools, several components of PBS would also be necessary in addition to a point and level system. For a summary of the components missing from a point and level system, as compared to PBS, see Table 1 .

\section{PBS Research in DTR Schools}

In a two-part study, Jolivette and colleagues (2008) implemented PBS first in residential school classrooms and then extended the PBS plan to student living units. The school program included several preparations for implementation and ongoing components, including (a) training teachers and staff, (b) developing a leadership team, (c) assuring staff buy-in, (d) establishing a data-based action plan, (e) developing a system to ensure high levels of fidelity for program implementation, and (f) monitoring data. The authors used office disciplinary referrals for data collection and organized a school-wide data system to ensure accuracy and ease of recording data.

One of the most interesting components of the Jolivette and colleagues (2008) study was the use of behavioral matrices. For example, the authors developed the STAR mnemonic $(\mathrm{S}=$ Show respect; $\mathrm{T}=$ Take responsibility; $\mathrm{A}=$
Accept adult directions; $\mathrm{R}=$ Respond appropriately). Each broad behavioral label was applied to specific school settings (e.g., classroom, hallway, bathroom, transition, etc.). Specifically, students were to Show respect in the library by using an inside voice, keeping the library clean and organized, and staying within the library room. Students would Take responsibility in the library by going directly to class and being on time, Accept adult directions by staying with staff and acting on the first prompt, and Respond appropriately by reporting problems to staff immediately. During the second part of the study, a similar matrix was developed for the living units.

The STAR matrices appropriately contextualized student behavior into the school and living unit settings. However, such an approach does expect students to integrate a high number of area-specific behaviors for both school and the living unit. While some overlap of expectations exists in each of the four STAR categories across settings, students must integrate about 45 different behavioral expectations throughout their school day and another setting specific list on the living unit. Schools attempting to use PBS may prefer to develop five to six rules that apply in a few consistent ways to all settings. For example, students could be expected to follow three rules in all school settings and living unit settings: (a) follow directions; (b) be safe; and (c) respect yourself and others. Be safe could refer to, for all school and unit settings, using words to solve problems, staying in the area defined by staff, keeping hands and feet to yourself, and walking when inside and during transitions.

In the Jolivette and colleagues (2008) study, the teachers also used components of explicit instruction to teach rules to students. Explicit or direct instruction (di) is an effective and recommended approach to teaching behavior to youth. The di approach includes "(a) review, (b) presentation, (c) guided practice, (d) corrections and feedback, (e) independent practice, and (f) weekly and monthly reviews" (Rosenshine \& Stevens, 1986, as cited in Gagnon \& Maccini, 2005, p. 2).

Three additional components of the PBS approach employed by Jolivette and colleagues (2008) were the use of tokens as positive reinforcers for following rules, ongoing progress monitoring, and treatment fidelity checks. The authors provided students with a token when they were "caught" following the rules and used progress monitoring by reviewing data, such as office disciplinary referrals, on when and where problem behaviors occurred, the types of behavior problems, and issues with specific students. Weekly review of data led to changes in policies and procedures. The researchers monitored adherence to the program using the School-Wide Evaluation Tool (Todd et al., 2003). The tool has several components that require a review of 


\section{TABLE 1}

\section{PBS Compared to a Combined Point and Level System}

\begin{tabular}{ll}
$\begin{array}{l}\text { Level of } \\
\text { intervention }\end{array}$ & PBS* $^{*}$ \\
\hline Primary & - Behavioral expectations defined \\
& - Behavioral expectations taught \\
& - Reward system for appropriate behavior \\
- Continuum of consequences for problem behavior & Cocilection and use of data for \\
& decision making
\end{tabular}

Level of intervention

- Behavioral expectations defined

Continuum of consequences for problem decision making

\section{Point and level system ${ }^{\star *}$}

- Clearly defined sequence of skills or performance criteria for advancement

- General rules and expectations for all students and specific rules and procedures that are responsive to group needs at each level in the system

- Basic privileges and rewards for all students and specific additional benefits for higher levels

- Systems of intervention to inhibit or suppress unacceptable behaviors

- System for continuous monitoring of performance

- System of communication for articulating program features and procedures with students, staff, parents, and other educators and agencies

- Clearly defined procedures for making transitions to advanced placement or less restrictive services/ settings (p. 5)

- Provision for differentiated environments and/or materials (small groups of at risk students)

- Progress monitoring for at risk students

- System for increasing structure and predictability

- System for increasing contingent adult feedback

- System for linking academic and behavioral performance

- System for increasing home/school communication

- Collection and use of data for decision making

Tertiary - Functional behavioral assessment

- Team-based comprehensive assessment

- Linking of academic and behavior supports

- Individualized intervention based on assessment information focusing on

(a) prevention of problem contexts

(b) instruction on functionally equivalent skills and instruction on desired performance skills

(c) strategies for placing problem behavior on extinction

(d) strategies for enhancing contingence reward of desired behavior

(e) use of negative or safety consequences if needed

- Collection and use of data for decision making
- Specific rules and procedures responsive to individual needs at each level in the system

- Provision for differentiated environments and/or materials (individual students)

- Individualized interventions, such as selfmanagement, should be embedded into point and level system (Cavalier, Ferretti, \& Hodges, 1997)

\footnotetext{
* Office of Special Education Programs, Center on Positive Behavioral Interventions and Support. (2007). Is school-wide positive behavior support and evidenced-based practice? A research summary. Eugene, OR: Author. Used with permission.

**Baaten, S., \& Ulman, J. (2004). Level systems: Constructing effective and ethical systems. Arden Hills, MN: Behavior Institute for Children and Adolescents. Used with permission.
}

records, interviews, and observations to evaluate whether staff are following implementation guidelines appropriately and with fidelity.

Little research focuses on the effects of PBS with older students outside a classroom situation, such as in DTR housing units. However, Jolivette and colleagues (2008) extended the PBS program to living units after first using PBS in the school. In modifying the program for the living units, the researchers altered the behavioral matrices. For example, they added bedroom expectations and adapted the reinforcement system so that the living units relied more on reinforcers related to student choice and freedom. 


\section{Juvenile Corrections Facilities (JCF)}

Like youth in DTR, youth in JCF have several unique and complicated characteristics. For example, according to two national studies, an average of $30 \%-44 \%$ of youth receive special education services, and, in some states, the rate exceeds 75\% (Gagnon, Barber, \& Van Loan, 2008; Quinn, Rutherford, Leone, Osher, \& Poirier, 2005). Four to seven times more youth in JCF are classified with disabilities than in regular public schools, and six times more youth in JCF have ED than in regular public schools (Gagnon, Barber, \& Van Loan; USDOE, 2007). Also, approximately $20 \%$ of school-age youth with ED are arrested, in detention, or on probation before exiting school (Snyder \& Sickmund, 2006), and $70 \%$ of these youth are arrested within three years of leaving school (U.S. Department of Health and Human Services, 1999). The high percentage of youth in JCF with a special education classification brings additional complications. For example, students with ED are more likely than nondisabled peers to be depressed and anxious (Newcomer, Barenbaum, \& Pearson, 1995).

Among youth with and without disabilities in JCF, a high percentage have mental disorders. In one study, $52 \%$ of youth involved with the juvenile justice system had a diagnosed mental disorder (Garland et al., 2001), and about half of youth involved in JCF have a substance use disorder (Teplin et al., 2002). Other studies confirm the high percentage of youth with mental disorders. Specifically, excluding conduct disorder, two thirds of males and three fourths of females met diagnostic criteria for one or more psychiatric disorders (Skowyra \& Cocozza, 2006; Teplin et al.). Moreover, a recent meta-analysis showed that, compared to youth in the general population, youth in JCF were (a) two to four times more likely to have ADHD, (b) girls were two to four times more likely to have major depression, and (c) boys were twice as likely to have major depression (Fazel, Doll, \& Langstrom, 2008).

Youth in JCF schools may also have a high incidence of conduct disorders, which may be particularly resistant to intervention (Underwood et al., 2008). In fact, more than half of youth have oppositional defiant disorder or conduct disorder (Teplin et al., 2002). Compared to youth in the general population, youth in JCF were about 10 times more likely to have conduct disorder or psychosis (Fazel et al., 2008).

Youth in JCF commonly have serious problems with substance abuse and suicidal ideation. The percentage of youth arrested for drug abuse violations has increased almost $20 \%$ from 1993 to 2004 (Snyder, 2005). In fact, about half of male detainees and almost half of female detainees have one or more substance use disorders (McClelland, Elkington, Teplin, \& Abram, 2004; Teplin, et al., 2002). Also, 1 in 10 youths in juvenile detention has had recent thoughts of suicide and another 1 in 10 has attempted suicide (Teplin et al.).
A key distinction between youth involved in juvenile corrections who have made a suicide attempt and those adolescent suicide attempters in the general population is that approximately two thirds of incarcerated youth attempters used violent means (e.g., cutting, hanging) that are more likely to succeed. In contrast about $85 \%$ of adolescents in the general population who attempt suicide do so by overdose, which has less likelihood of resulting in suicide completion (Penn, Esposito, Schaeffer, Fritz, \& Spirito, 2003). In fact, youth in custody are three to five times more likely to complete suicide than youth in the general population (Farand, Chagnon, Renaud, \& Rivard, 2004; Gallagher, \& Dobrin, 2006).

In addition to having mental disorders, youth in JCF commonly experience traumatic events in their lives. For example, many youth in juvenile corrections witness violence or are the victims of violence. Specifically, $11 \%$ of detained youth were identified as having posttraumatic stress disorder (PTSD) and about $90 \%$ of youth have witnessed someone being hurt very badly or killed (Abram, Teplin, Charles, Longworth, McClelland, \& Dulcan, 2004; Teplin et al., 2002). Shelton (2000) also reported that $16 \%$ of youth had themselves sustained a gunshot or stab wound in the previous year. Youth involved in the juvenile corrections system also have a high incidence of abuse: of females, $70 \%$ have been physically abused and $70 \%$ sexually abused, and of males, over $50 \%$ have experienced physical abuse and 20\% have been sexually abused (Evans, Alpers, Macari, $\&$ Mason, 1996). Shelton also reported that $35 \%$ of detained youth reported being physically abused, and $18 \%$ reported being sexually abused.

\section{Common Approaches to Student Behavior in Juvenile Corrections}

Regrettably, in JCF the culture of security, control, and punishment often prevails over research on effective approaches to student behavior (Barton \& Butts, 2008; Nelson, Sugai, \& Smith, 2005). Youth with and without disabilities in juvenile corrections must be actively engaged in the learning process. However, the attitude held by many in corrections is that confinement should not be a positive experience where appropriate behaviors are reinforced (Nelson et al.); rather, isolation and exclusion predominate as the reaction to juvenile misbehavior. Exclusionary approaches, however, do not improve student behavior (Sailor, Stowe, Turnbull, \& Kleinhammer-Tramill, 2007). Unfortunately, empirical studies that target student maladaptive behavior in JCF seem to be nonexistent. A search of behavioral interventions and juvenile corrections in the PsychInfo database revealed no peer reviewed published research. Given the complex characteristics of youth, the lack of research on behavioral supports for these youth is disturbing. 
Although information is insufficient concerning behavioral interventions for youth in JCF, some evidence shows that youth may have access to psychopharmacologic treatment. In a study of a Department of Juvenile Probation residential program, Ryan and colleagues, (2008) reported that $94 \%$ of youth were receiving medication.

\section{PBS Research in Juvenile Corrections}

Despite the overall dearth of information concerning student behavior in JCF, a few studies have focused on the implementation of PBS in JCF. In contrast to the usual harsh, punitive, and reactionary approaches to student behavior in JCF schools, PBS provides a more coordinated, proactive, and positive approach (Read et al., 2008). Although PBS is being used in 286 alternative and juvenile correctional schools (Danielson et al., 2007 as cited in Read et al., 2008), only two reports describing PBS implementation are available (Sidana, 2006). The two reports' examples do not describe the numerous considerations and details that effective PBS implementation must address (e.g., modification of behavioral programming based on analysis of behavioral data). However, the study summaries do show that PBS is an effective approach to student behavior in JCF.

Sidana (2006) reported on The Illinois Youth Center's (IYC) implementation of PBS at the Harrisburg boys' prison. The universal interventions included providing tickets to youth for appropriate behavior. Students could exchange tickets for tangible and activity reinforcement. The system also included both secondary and tertiary interventions. For example, youth had access to mentors as a secondary intervention, and had tertiary interventions based on the individual student's need. The implementation of PBS resulted in a decline in minor and major infractions at the school, and physical altercations among students declined from 32 per month to zero in three years.

Sidana (2006) also summarized implementation of PBS at The Iowa Juvenile Home (IJH), where the school-wide behavioral program provided youth with courage slips that could be earned by meeting personal goals and school expectations. The administrators also retained the school plan that provided negative consequences for significant behavioral infractions. Results showed that following PBS implementation, student seclusion and restraint declined by $73 \%$, and the average rate of disciplinary removals declined by $50 \%$.

\section{Alternative Schools}

The U.S. has about 10,000 secondary alternative schools (Market Data Retrieval, personal communication, 2007). The schools and the students served in them vary widely. However, among the most common reasons for youth enrollment in alternative schools are social-emotional problems, truancy, home referrals, and verbal and physical aggression (Foley \& Pang, 2006; Kleiner, Porch, \& Ferris, 2002). We also know that, although youth can be placed in an alternative school as an interim placement lasting just 45 days (see IDEIA, 2006, C.F.R. 71. 300.530), a majority of youth are enrolled for seven months or more (Lehr et al., 2004). Additionally, Grunbaum and colleagues (2000) identified that, of students in alternative schools, in the 30 days preceding the survey, $32.9 \%$ had carried a weapon, $50 \%$ had engaged in heavy drinking of alcohol, 53\% had used marijuana, and $15 \%$ had used cocaine. Moreover, $25 \%$ had considered suicide and $16 \%$ had attempted suicide. These researchers also noted that the prevalence of most risk behavior was significantly higher among youth in alternative schools than youth in the general population. Compared to other adolescents, youth in alternative schools are three times more likely to commit acts of vandalism, assault, or shoplifting, and twice as likely to be involved in a gang (Fulkerson, Harrison, \& Hedger, 1998). Moreover, about 22\% of alternative school students have been involved with a law enforcement agency (Davis, Brutsaert-Durant, \& Lee, 2002).

Available information also reveals that a high percentage of youth in alternative schools are classified with a disability. Researchers (Gorney \& Ysseldyke, 1993; Kleiner, Porch, \& Farris, 2002) have reported that $12 \%-20 \%$ of students in alternative schools are classified as having a disability and as many as $50 \%-84 \%$ are classified as ED (Gorney \& Ysseldyke; Quinn \& Poirier, 2006; Swarts, 2004). About another $10 \%$ of students are classified with learning disabilities, ADD, and ADHD (Foley \& Pang, 2006).

\section{Common Approaches to Student Behavior in Alternative Schools}

Many consider an alternative school to be a last chance effort to help troubled youth and prevent them from dropping out of school (Raywid, 1994). Although the characteristics of alternative schools and how they approach student behavior remain largely unknown, some evidence suggests that these schools have a great deal of freedom and rely on site-based management to operate off-campus facilities (Foley \& Pang, 2006). Alternative schools commonly provide environmental variations in an attempt to support students. Adjustments may include small class and school size, a low student-teacher ratio, and varied schedules and hours of operation (Lehr \& Lange, 2003). Fewer than one-third of alternative schools actively involve parents, but other professional support is more common (e.g., social workers, counselors, paraprofessionals, school nurses, school psychologists, vocational educators) (Foley \& Pang). That a variety of professionals may be involved in supporting youth in alternative schools is encouraging, but less than half of the schools include coordinated wraparound services, which is of concern (Foley \& Pang). 


\section{PBS Research in Alternative Schools}

Currently, no published empirical studies have addressed the issue of implementing PBS in alternative schools. However, the effectiveness of PBS for troubled youth in regular public schools and in JCF and the common characteristics of youth across exclusionary settings make a strong case for using PBS in alternative schools. Exclusionary schools are complex, and application of PBS to alternative school settings will require cross-agency collaboration to ensure that the planning, implementation, and data-based modification all consider the unique characteristics of both the setting and the students.

\section{OVERCOMING BARRIERS}

Any setting, whether public school or exclusionary, faces complications in applying PBS. Careful planning and implementation can address many of these common barriers. For instance, ensuring that school personnel are aware of the potential benefits of PBS (Luiselli et al., 2005; Metzler et al., 2001; Netzel \& Eber, 2003; Oswald et al., 2005; Scott, 2001) and including staff members in action-plan development (Oswald et al.; Scott; Turnbull et al., 2002) can achieve staff buy-in. Using existing sources of data, such as referral and suspension data, makes data collection and data-based decision making easier (Luiselli et al.; Scott $\&$ Barrett, 2004). Researchers have identified a number barriers to PBS implementation (Lohrman, Forman, Martin, \& Palmieri, 2008). Table 2 describes five common reasons for resistance to behavioral intervention at the universal/primary level and ways to overcome these barriers. Additional barriers include the need for staff training and securing the resources needed to effectively implement the action plan.

\section{Staff Training}

One need in each of the settings of interest is professional development. Teachers and other professionals may not feel prepared to effectively address student behavior problems except in punitive ways. Consistent and appropriate use of PBS rests heavily on the understanding, agreement, and collaboration of professionals from a number of fields, with the national inservice training model including the following (Dunlap et al, 2000, p. 16):

1. The training targets a multidisciplinary audience and delivery promotes collaboration among the participants.

2. It uses a case study format so that the participants are able to apply information to benefit an individual in the community.

3. It incorporates a dynamic training process that engages participants in practical activities and assists them in developing generalizable skills.

4. It is comprehensive, addressing a broad range of topics associated with positive behavior support.

5. It contains elements specifically focused on promoting community building so that systems can be enhanced to promote ongoing support for participants and extend positive behavior support efforts.

Another important element is the provision of crosstraining staff. "The blending of resources, language, decision making, and best practices across systems and disciplines remains a complex and sometimes daunting task" (Eber, Sugai, Smith, \& Scott, 2002, p. 172). However, com-

\section{TABLE 2}

\section{Broad Barriers to Universal Interventions and Strategies*}

Barrier Strategy

Lack of administrator direction and leadership

Skepticism of the need for the intervention

Hopelessness that change can occur

Differences in philosophy

Disenfranchisement of staff with each other and with the administrator
Principal should provide clear vision and meet with staff regularly to share information, solve problems, and provide support

Identify the need for action based on data

Provide examples of successful schools and continue to share data with staff following implementation

Find common ground based on research-based approaches to student behavior

Provide opportunities for collaboration with plan development and implementation; share success stories; tackle difficult problems collaboratively

\footnotetext{
* This table was modified from "Understanding school personnel's resistance to adopting schoolwide positive behavior support at the universal level of intervention," by S. Lohrman, S. Forman, S. Martin, \& M. Palmieri, 2008, Journal of Positive Behavior Intervention OnlineFirst, Retrieved September 3, 2008, from http://jpbi.sagepub.com. Used with permission.
} 
bined professional development with educators, mental health professionals, and correctional professionals will provide a common understanding of students, develop a common vocabulary, and result in collaborative program development that includes PBS and additional supports for students, as needed (Skowyra \& Cocozza, 2006). The next step - cross-agency collaboration -is essential for interventions to have sufficient consistency and scope (Scott et al., 2002).

\section{Securing Resources}

To provide the three tiers of services included within PBS, schools need both funding and resources (OSEP, 2004). Planning teams may use existing school and district resources (Turnbull et al., 2002). For instance, school guidance counselors may already provide many small group interventions such as social skills programs. School districts may already employ behavior specialists, social workers, and mental health counselors, who can help provide individualized interventions at tier three of PBS. In some schools, parent-teacher organizations may be able to fund reward systems. If funding cannot be obtained, free time or extended lunch time can be used as a low-cost reward as part of a group contingency (Scott, 2001).

Low income schools face several additional challenges (Turnbull et al., 2002). Funding may be more difficult to obtain and more students may need costly tier two and three services. These schools may need to obtain additional funding and support from the school district. School districts should be willing to provide short-term funding for PBS, because PBS reduces the numbers of students requiring tier two and three services (Turnbull et al.), increases academic achievement (Lassen et al., 2006; Luiselli et al., 2005; McIntosh et al., 2006), and frees up instructional time (Scott \& Barrett, 2004). Over time, school-wide PBS thus has the potential to save money by reducing the need for costly academic and behavioral interventions.

\section{Overcoming Barriers in Exclusionary Settings}

\section{High Percentage of Youth With Disabilities}

The high percentage of youth with disabilities, particularly those with ED, can profoundly affect the implementation of PBS and the need for additional services. For example, in a typical school $80 \%$ of the student population requires universal intervention, approximately $15 \%$ of the student population receives secondary interventions, and about $5 \%$ need individualized tertiary interventions (Walker et al., 2005). In contrast, Nelson and Quinn (2007) reported on a JCF where about $24 \%$ of youth needed only universal interventions, while $23 \%$ required secondary, and 53\% needed tertiary interventions. In a residential school, these researchers also noted that a high percentage of youth needed secondary or tertiary interventions. Specifically, $25 \%$ required secondary interventions and $21 \%$ needed tertiary interventions. The high percentage of youth needing secondary and tertiary interventions can place a strain on teachers and resources.

Several considerations can address the fact that a high percentage of youth have special needs. First, while a high percentage may require secondary or tertiary interventions, not all youth in exclusionary settings need these levels of intervention. Rather, all levels of PBS should be available to youth, with the level of support to any student resulting from a data-based decision-making process (Nelson, Scott, Gagnon, Jolivette, \& Sprague, 2008; Scott et al., 2002). Primary prevention is important, for "without primary intervention, the number of students requiring secondary and tertiary strategies likely will tax available intervention resources beyond capacity" (Scott et al., p. 537). However, a high percentage of youth in exclusionary settings have significant behavioral needs, and more staff support may be needed than in typical schools. Administrators in exclusionary settings must recognize the demands PBS places on educators and other staff (e.g., corrections officers) and provide the necessary support, such as a PBS facility coordinator (Read et al., 2008). Moreover, staff must understand how PBS or its components will supplant other less effective and less efficient approaches (Read et al.). To reduce the impact on staff, researchers also recommend progressive implementation where, for example, the program could initially be implemented solely in a facility's school (Nelson et al., 2005).

\section{Youth Mental Disorders}

The high percentages of youth in exclusionary settings with mental disorders, at risk for suicide, drug abuse, history of abuse, and exposure to violence creates a clear need for supports in addition to PBS, including (a) appropriate mental health and drug abuse screening and (b) access to emergency and ongoing research-based mental health services that include families (Skowyra \& Cocozza, 2006). In particular, comprehensive mental health screening upon entry into a program often receives insufficient attention (The President's New Freedom Commission on Mental Health, 2003).

A comprehensive description of research-based approaches to addressing student mental health needs is beyond the scope of our current discussion. However, we would like to mention four approaches that could complement PBS, given the characteristics of youth in DTR, JCF, and alternative school settings: (a) cognitive behavioral interventions, (b) psychopharmacologic treatment, (c) multiagency collaboration, and (d) merging PBS with existing behavioral programs.

Cognitive behavioral interventions are particularly help- 
ful: "Cognitive behavior modification is based on the proposition that inner speech mediates behavior and that, by using language to alter cognition, behavior can change" (Gagnon \& Mayer, 2004, p. 9). The underlying premise is that improvements in appropriate behavior will occur upon (a) correction of errors in thinking, (b) reduction of deficits in social information-processing skills, and (c) improvements in regulating, controlling, and managing their own behavior (Gerber \& Solari, 2005; Guerra, Boxer, \& Kim, 2005). A cognitive behavioral approach is effective for individual youth and their families (Hoagwood, Burns, Kiser, Ringeisen, \& Schoenwald, 2001), and evidence suggests that counseling, which includes components such as anger management, social skills training, and career training, is effective in reducing recidivism into the juvenile corrections system (Kadish, Glaser, Calhoun, \& Risler, 1999).

The combination of cognitive and behavioral interventions is also effective for youth with drug abuse problems, although effective intervention for youth drug-abuse disorders should address multiple areas including problems with school, peers, and family as well as elements of relapse prevention (Dowden, 2003). Other elements are also important to effective substance abuse programs, including (a) treatment for at least one year, (b) family involvement, (c) life skills and abstinence training, and (d) aftercare that includes self-help and support groups (Larson \& Turner, 2002).

Youth with combinations of disorders, such as disruptive disorders with comorbid depression or anxiety, may also garner significant benefit from cognitive-behavioral approaches (Forness, 2003). Specifically, youth can be reinforced for using certain techniques that address problem behavior, such as problem-solving procedures. Teaching cognitive strategies in combination with effective behavioral contingencies decreases such behaviors as hyperactivity/impulsivity and disruption/aggression and increases the frequency of more prosocial behavior (Smith, Lochman, \& Daunic, 2005).

Some evidence suggests that teachers can support counselors and psychologists in employing cognitive-behavior interventions for youth with depressive disorder (Maag \& Swearer, 2005). For example, teachers trained in cognitive-behavior interventions such as problem-solving or selfmonitoring could help youth who have difficulties with negative self-statements. Students can be prompted to use particular problem-solving strategies and be reinforced for using them, as well as for recognizing and altering negative self-statements.

Psychopharmacologic treatment is another important tertiary approach to assisting some youth. While PBS has the potential to greatly improve student behavior, for some youth, combined psychopharmacologic treatment and behavioral interventions can result in even greater behavioral and academic gains (Forness, 2003; Forness, Kavale, \& Davanzo,
2002). Psychopharmacologic treatment may be particularly helpful in cases where youth do not respond to behavioral interventions (Forness et al.). In fact, for many youth with mental disorders such as ADHD, psychotropic medications are related to improvements in educational achievement (Barbaresi, Katusic, Colligan, Weaver, \& Jacobsen, 2007). Combined medication and cognitive-behavioral treatment for youth with ADHD, depression, and anxiety have resulted in the greatest behavioral gains (Forness, Freeman, \& Paparella, 2006).

However, the decision to prescribe medication for a youth carries certain concerns that require monitoring, including "adverse side effects, inadequately trained physicians, variability in referrals, direct marketing of pharmaceuticals, and complex diagnostic dilemmas" (Forness et al., 2006, p. 292). Moreover, additional research is needed to support the effectiveness of psychopharmacologic treatment, and when making comparisons between psychopharmacologic and nonmedication treatments. Some researchers express methodological concerns for nonmedication interventions that assess the impact on academic achievement of youth with ADHD (Trout, Linemann, Reid, \& Epstein, 2007). Additional concerns exist regarding the extent to which teachers and other nonmedical professionals can or should be involved in medication management. However, teachers commonly and appropriately play an active role by providing information regarding medication efficacy to physicians (Ryan, Reid, \& Ellis, 2008).

\section{Multiple Agency Collaboration}

Youth involvement with a number of agencies may complicate PBS implementation and provision of support services for youth in DTR, JCF, and alternative school settings (Nelson et al., 2005). For example, youth in JCF often need a broad range of services and interagency collaborative efforts that include the exclusionary school facility, juvenile court, public school, mental health, family, and other services (Houchins, Jolivette, Wessendorf, McGlynn, \& Nelson, 2005). PBS is likely to be unsuccessful if the program rests solely on the understanding of a few special educators (Gerber \& Solari, 2005). Collaboration is particularly important, as professionals from various organizations (e.g., secure-care staff) may have goals and philosophies that are contrary to PBS, such as a sole focus on control and punishment of student behavior.

To address concerns regarding insufficient multiagency collaboration, professionals across agencies must develop a common philosophy; shared priorities; consistent approaches to treatment; a common language; and a commitment to research-based, positive, and proactive approaches to student behavior (Read et al., 2008). Additionally, to maintain fidelity of PBS implementation despite staff turnover, facilities should formally adopt behavioral policies and procedures that align with the PBS model (Jolivette et al., 2008). For example, 
one regular school codified its procedures in a Procedures and Protocol Handbook (McCloud, 2005). Additionally, ensuring individual accountability for following PBS procedures will support appropriate implementation (Read et al.).

\section{Wraparound and Integrated Systems Intervention Models}

The wraparound planning process rests on a system of care or community-based approach to providing comprehensive and integrated services through multiple professionals and agencies in collaboration with families (Scott \& Eber, 2003; Stroul \& Freidman, 1986). In essence, wraparound planning is an individually tailored integration of services to surround the individual with support from all avenues: school, community, and family. Simple involvement by a larger range of service providers does not constitute wraparound; rather, wraparound refers to a fully integrated and collaborative structure to lead the provision of services. The importance of collaborative structures to (a) lead and manage integration of wraparound implementation across service sectors, (b) define target populations, and (c) ensure flexibility across disciplines is well documented (VanDenBerg \& Grealish, 1996; Goldman \& Faw, 1999). The principles of wraparound fit well within a conceptualization of PBS, sharing essential features and principles. Table 3 presents a summary of how the essential elements of wraparound apply to PBS (adapted from Scott \& Eber).

Wraparound has successfully improved social/behavioral and school functioning of youth and prevented more restrictive living and school placements for students with significant emotional and behavioral disorders (EBD) in mental health, juvenile justice, child welfare, and special education (Burns et al., 2000; Eber, Osuch, \& Reditt, 1996). However, wraparound also has served as early intervention for students identified as at risk for ED (Eber \& Nelson, 1997), which includes the students who typically end up in exclusionary school settings.

The perspectives and voice of the individual, the family, and others who have the most direct contact with the individual are considered vital in the design of supports, services, and interventions. In this manner, the wraparound process

TABLE 3

Key Features of PBS Across Intervention Levels (Scott \& Eber, 2003)

\section{Key features of PBS} and wraparound

Conceptualization of lifestyle change

Foundation in behavioral science

Reliance on full continuum of validated and practical intervention practices

\section{School-wide PBS process (primary)}

Gain school-wide consensus regarding expectations and the steps necessary to maximize success across all students. Monitor behavior across the school to evaluate system.

Collect and analyze school-wide data to determine predictable relationships between the environment and behavior. Develop functional and appropriate instruction, facilitation, and consequences across all students.

Use explicit instruction and develop instructional routines and physical arrangements/placements that predict school-wide student success four times more often than failure. Design strategies unique to the school but practical and realistic for all teachers and the maximum number of students.

Use data to make policy and procedural decisions. Expect, monitor, and reinforce proactive procedures across all school stakeholders for all students in the school.
Individual PBS process

(secondary and tertiary)

Gain collaborative team consensus regarding individualized expectations and the steps necessary to maximize small group or individual student success. Monitor individual or small group behavior to evaluate plan.

Collect and analyze student data to determine predictable relationships between environment and behavior. Develop functional and appropriate instruction, facilitation, and consequences for small group and individual students.

Use explicit instruction and develop instructional routines and physical arrangements/placements that predict individual and small group student success four times more often than failure. Design strategies unique to individual student needs but practical and realistic for involved teachers and students.

Use data to make policy and procedural decisions. Expect, monitor, and reinforce proactive procedures across all involved stakeholders for an individual or small group of students. 
involves the larger environment in developing plans that are collaborative across systems rather than top-down and that are calculated to facilitate success in the natural environment. The concept of wraparound is similarly involved at the primary level in that everyone invested in an intervention outcome is included in the design of the intervention elements (Scott \& Eber, 2003, p. 135)

\section{Merging PBS and Existing Behavior Programs}

Researchers recommend incorporating PBS into existing treatment or discipline models (Nelson et al., 2008). For example, a PBS model must integrate specific policies and procedures of the Department of Corrections (DOC) to maintain safety and security in JCF. However, program components that are merged with PBS, such as DOC behavioral plans designed to ensure safety, must be grounded in research-based approaches and not focus solely on punitive responses to student behavior.

Difficulties with merging PBS and other behavioral programs may exist with facility settings outside of the classroom, such as living units (Jolivette et al., 2008). Unfortunately, little research concerns the use of PBS outside of the classroom environment at the secondary level, especially in exclusionary settings. Yet, in the research that does exist, researchers stress the importance of progressive implementation across facility settings and cross-training professionals to assist in nonclassroom implementation of PBS (Jolivette et al.).

The extent to which DTR, JCF, and alternative schools use a form of point and level system to promote positive student behavior is relatively unknown. Many criticisms of level systems relate to a lack of individualized or tertiary interventions, as well as the need for cognitive interventions that teach new or replacement behaviors to students (Johns, Crowley, \& Guetzloe, 2002; Scheuermann \& Webber, 1996). However, a point system and level system have the potential to be a behavioral framework combined with PBS if these and other previously noted concerns are addressed.

\section{FINAL THOUGHTS}

The implementation of PBS in exclusionary school settings needs additional research. Also, a need continues for research to identify the extent to which any subcomponent of PBS provides added benefit and to focus on secondary interventions for students in a variety of educational placements (Forness, 2005). However, given the number of youth currently served in exclusionary settings, practicality requires that implementation of PBS begin, and that we rely on effective principles of behavior management, including a positive, proactive, consistently implemented, and comprehensive plan to promote positive student behavior.

\section{DTR Resources}

\section{Books/Articles:}

Jolivette, K., Kennedy, C., Puckett-Patterson, D., \& Houchins, D. E. (2008). Implementing a two-phase $24 / 7$ SWPBS program in a residential facility for students with severe emotional and behavioral disorders and mental health needs. Manuscript submitted for publication.

\section{Organizations/Websites:}

American Association of Children's Residential Centers; see http://www.aacrc-dc.org/

\section{JCF Resources}

\section{Books/Articles:}

Sidana, A. (2006). PBIS in juvenile justice settings. Washington DC: The National Evaluation and Technical Assistance Center for the Education of Children and Youth who are Neglected, Delinquent, and At Risk (NDTAC). Retrieved July 21, 2008 from http://www. neglected-delinquent.org/nd/resources/spotlight/spotlight 200601b.asp

Nelson, C. M., Scott, T. M., Gagnon, J. C., Jollivette, K., Sprague, J. (2008). Positive behavior support in the juvenile justice system. Positive Behavioral Interventions and Supports Newsletter. Eugene, OR: Office of Special Education Programs Center on Positive Behavioral Interventions and Supports. Available at http:// www.pbis.org/news/New/Newsletters/Newsletter43.aspx

\section{Organizations/Websites:}

The National Evaluation and Technical Assistance Center for the Education of Children and Youth who are Neglected, Delinquent, and At Risk (NDTAC). see http://www.neglected-delinquent.org/nd/default.asp

National Center on Education, Disability and Juvenile Justice (EDJJ), see http://www.edjj.org/

Office of Juvenile Justice and Delinquency Prevention (OJJDP), see http://ojjdp.ncjrs.org/

\section{Alternative School Resources}

\section{Organizations/Websites:}

The Alternative Schools Project, see http://ici.umn.edu/ alternativeschools/project/default.html

\section{FIGURE 2 PBS and exclusionary school resources}

In light of the unique characteristics of youth in DTR, JCF, and alternative schools, we must recognize the need to combine PBS with a range of highly individualized interventions, such as mental health services, cognitive behavioral interventions, and psychopharmacologic treatment. Moreover, effective support for youth will require crossagency collaboration, assurances of treatment/behavioral plan implementation fidelity, frequent collection and use of 
behavioral data, and ongoing and comprehensive staff training. Practically speaking, implementation should begin with small changes that are likely to produce positive and significant results without overwhelming staff (Read et al., 2008).

Although progress may be slow and incremental, youth in DTR, JCF, and alternative school settings clearly have a significant need for research-based universal, secondary, and tertiary interventions that include PBS. Provision of PBS and appropriate supports are necessary if these youth are to successfully reintegrate into school, the community, and the workforce.

\section{REFERENCES}

Abram, K. M., Teplin, L. A., Charles, D. R., Longworth, S. L., McClelland, G. M., \& Dulcan, M. K. (2004). Posttraumatic stress disorder and trauma in youth in juvenile detention. Archives of General Psychiatry, 61, 403-410.

American Psychiatric Association. (1994). Diagnostic and statistical manual of mental disorders (4th ed.). Washington, DC: Author.

Armstrong, M., Grosser, R., \& Palma, P. (1992). At the crossroads: Expanding community-based care for children and families (The New York State plan for children and families mental health services). New York: New York Office of Mental Health.

Barbaresi, W. J., Katusic, S. K., Colligan, R. C., Weaver, A. L., \& Jacobsen, S. J. (2007). Modifiers of long-term school outcomes for children with attention-deficit/hyperactivity disorder: Does treatment with stimulant medication make a difference? Results from a population-based study. Journal of Developmental \& Behavioral Pediatrics, 28, 274-287.

Barton, W. H., \& Butts, J. A. (2008). Building on strength: Positive youth development in juvenile justice programs. Chicago: Chapin Hall Center of Children at the University of Chicago.

Barnoski, R. (2001). Foundations for learning: Safe and Civil Schools Project: Summary of evaluation findings. Washington State Institute for Public Policy: Olympia, WA. Retrieved January 15, 2008, from site: http://wsipp.wa.gov/pub.asp?docid=01-10-2201

Bohanon, H., Fenning, P., Carney, K. L., Minnis-Kim, M. J., AndersonHarriss, S., Moroz, K. B., et al. (2006). Schoolwide application of positive behavior support in an urban high school: A case study. Journal of Positive Behavior Interventions, 8, 131-145.

Bowman, D. H. (2001, May 2). Survey of students documents the extent of bullying. Education Week on the Web. Retrieved October 28, 2008, from http://www.edweek.org

Braaten, S., \& Ulman, J. (2004). Level systems: Constructing effective and ethical systems. Arden Mills, MN: Behavioral Institute for Children and Adolescents. Retrieved July 21, 2008, from http:// www.behavioralinstitute.org/Resources/Level\%20Systems\%20Ha ndout_SBraaten_MN05.pdf

Burns, B. J., Schoenwald, S. K., Burchard, J. D., Faw, L., \& Santos, A. B. (2000). Comprehensive community-based interventions for youth with severe emotional disorders: Multisystemic therapy and wraparound process. Journal of Child and Family Studies, 9, 283-314.

Cavalier, A. R., Ferretti, R. P., \& Hodges, A. E. (1997). Self-management within a classroom token economy for students with learning disabilities. Research in Developmental Disabilities, 18, 167-178.

Christle, C. A., Jolivette, K., \& Nelson, C. M. (2007). School characteristics related to high school dropout rates. Remedial and Special Education, 28, 325-339.
Danielson, L., Cobb, B., Sanchez, S., \& Horner, R. (2007). Evidencebased practices: A technical assistance perspective. Presentation as part of the 2007 Office of Special Education Projects Project Directors' Conference, Washington, DC.

Davis, W. E., Brutsaert-Durant, L., \& Lee, R. M. (2002). Alternative education programs in Maine: A further investigation of their impact upon serving students considered to be at risk and students with disabilities. Orono, ME: Institute for the Study of Students at Risk, College of Education and Human Development, The University of Maine.

Dowden, C. (2003). The effectiveness of substance abuse treatment with young offenders. Youth Justice Research Series. Ottawa, Ontario Canada: Department of Justice-Canada. Retrieved April 25, 2006, from http://www.justice.gc.ca/en/ps/rs/rep/2003/rr03yj-1/rr03yj_1. pdf

Duncan, B. B., Forness, S. R., \& Hartsough, C. (1995). Students identified as seriously emotionally disturbed in school-based day treatment: Cognitive, psychiatric, and special education characteristics. Behavioral Disorders, 20, 238-252.

Dunlap, G., Heineman, M., Knoster, T., Fox, L., Anderson, J., \& Albin, R. W. (2000). Essential elements of inservice training in positive behavior support. Journal of Positive Behavior Interventions, 2, 22-32.

DuPaul, G. J. (2007). School-based interventions for students with attention deficit hyperactivity disorder: Current status and future directions. School Psychology Review, 36, 183-194.

Eber, L. \& Nelson, C. M. (1997). Integrating services for students with emotional and behavioral needs through school-based wraparound planning. American Journal of Orthopsychiatry, 67, 385-395.

Eber, L., Osuch, R., \& Redditt, C. A. (1996). School-based applications of the wraparound process: Early results on service provision and student outcomes. Journal of Child and Family Studies, 5, 83-99.

Eber, L., Sugai, G., Smith, C. R., \& Scott, T. M. (2002). Wraparound and positive behavioral interventions and supports in the schools. Journal of Emotional and Behavioral Disorders, 10, 171-180.

Evans, W., Alpers, E., Macari, D., \& Mason, A. (1996). Suicide ideation, attempts and abuse among gang and nongang delinquents. Child and Adolescent Social Work Journal, 13, 115-126.

Farand, L., Chagnon, F., Renaud, J., \& Rivard, M. (2004). Completed suicides among Quebec adolescents involved with juvenile justice and child welfare services. Suicide and Life-Threatening Behavior, 34, 24-35.

Farrell, D. T., Smith, S. W., \& Brownell, M. T., (1998). Teacher perception of level system effectiveness on the behavior of students with emotional or behavioral disorders. Journal of Special Education, 32, 89-98.

Fazel, S., Doll, H., \& Langstrom, N. (2008). Mental disorders among adolescents in juvenile detention and correctional facilities: A systematic review and metaregression analysis of 25 surveys. Journal of the American Academy of Child and Adolescent Psychiatry, 47, 1010-1019.

Foley, R. M., \& Pang, L. (2006). Alternative education programs: Program and student characteristics. High School Journal, 89(3), 10-21.

Forness, S. R. (2003). Parting reflections on education of children with emotional and behavioral disorders. Behavioral Disorders, 28, 198-201.

Forness, S. R. (2005). The pursuit of evidence-based practices in special education for children with emotional or behavioral disorders. Behavioral Disorders, 30, 311-330.

Forness, S. R., Freeman, S. F. N., \& Paparella, T. (2006). Recent randomized clinical trials comparing behavioral interventions and psychopharmacologic treatment for students with EBD. Behavioral Disorders, 31, 284-296. 
Forness, S. R., Kavale, K. A., \& Davanzo, P. A. (2002). The new medical model: Interdisciplinary treatment and the limits of behaviorism. Behavioral Disorders, 27, 168-178.

Fulkerson, J. A., Harrison, P. A., \& Hedger, S. A., (1998). Alternative schools and area learning centers: 1998 Minnesota student survey. St. Paul, MN: Minnesota Department of Human Services.

Gagnon, J. C., Barber, B. R., \& Van Loan, C. L. (2008). Juvenile correctional schools: Characteristics and approaches to curriculum. Unpublished manuscript.

Gagnon, J. C., \& Leone, P. E. (2006). Day and residential schools for children with emotional and behavioral disorders: Characteristics of educators and students. Education and Treatment of Children, 29(1), $51-78$.

Gagnon, J. C., \& Maccini, P. (2005). Direct instruction in mathematics for youth with learning disabilities in middle school (pp. 1-6). Washington, DC: The Access Center: Improving Outcomes for all Students K-8. Available at http://www.k8accesscenter.org/training_resources/directinstructionmath.asp

Gagnon, J. C., \& Mayer, M. (2004). Educating juveniles with disabilities in correctional settings. In L. M. Bullock, R. A. Gable, \& K. J. Melloy (Eds.), Fifth CCBD mini-library series (pp. 1-59). Arlington, VA: Council for Children with Behavioral Disorders.

Gagnon, J. C., \& Richards, C. (2008). Making the right turn: A guide about youth involved in the juvenile corrections system. Washington, DC: National Collaborative on Workforce and Disability for Youth, Institute for Educational Leadership.

Gagnon, J. C., Van Loan, C. L., \& Barber, B. R. (2008). Secondary day treatment and residential schools for students with emotional and behavioral disorders: Characteristics and approaches to curriculum. Manuscript submitted for publication.

Gallagher, C. A., \& Dobrin, A. (2006). Deaths in juvenile justice residential facilities. Journal of Adolescent Health, 38, 662-668.

Garland, A. E., Hough, R. L., McCabe, K. M., Yeh, M., Wood, P. A., \& Aarons, G. A. (2001). Prevalence of psychiatric disorders in youths across five sectors. Journal of the American Academy of Child and Adolescent Psychiatry, 40, 409-418.

Gerber, M. M., \& Solari, E. J. (2005). Teaching effort and the future of $\operatorname{cog}$ nitive-behavioral interventions. Behavioral Disorders, 30, 289-299.

Goldman, S., \& Faw, L., (1999). Three wraparound models as promising approaches. In B. J. Burns \& S. K. Goldman, (Eds.), Promising practices in wraparound for children with serious emotional disturbance and their families (pp. 34-60). Washington, DC: Center for Effective Collaboration and Practice, American Institute for Research.

Gorney, D., \& Yssledyke, J. E. (1993). Students with disabilities use of various options to access alternative schools and area learning centers. Special Services in the Schools, 7(1), 125-143.

Greenbaum, P. E., Dedrick, R. F., Friedman, R. M., Kutash, K., Brown, E. C., Lardieri, S. P., \& Pugh, A. M. (1996). National adolescent and child treatment study (NACTS): Outcomes for children with serious emotional and behavioral disturbance. Journal of Emotional and Behavioral Disorders, 4, 130-146.

Grunbaum, J. A., Kann, L., Kinchen, S. A., Ross, J. G., Gowda, V. R., Collins, J. L., \& Kolbe, L. J. (2000). Youth risk behavior surveillance: National alternative high school youth risk behavior survey, United States 1998. Journal of School Health, 70, 5-17.

Guerra, N. G., Boxer, P., \& Kim, T. E. (2005). A cognitive-ecological approach to serving students with emotional and behavioral disorders: Application to aggressive behavior. Behavioral Disorders, 20, 277-288.

Hoagwood, K. J., Burns, B. J., Kiser, L., Ringeisen, H., \& Schoenwald, S. K. (2001). Evidenced-based practice in child and adolescent mental health services. Psychiatric Services, 52, 1179-1189.
Hooper, S. R., Murphy, J., Devaney, A., \& Hultman, T. (2000). Ecological outcomes of adolescents in a psychoeducational residential treatment facility. American Journal of Orthopsychiatry, 70, 419-500.

Houchins, D. E., Jolivette, K., Wessendorf, S., McGlynn, M., \& Nelson, C. M. (2005). Stakeholders' view of implementing positive behavioral support in a juvenile justice setting. Education and Treatment of Children, 28, 380-399.

Individuals With Disabilities Education Act. 20 U.S.C. 1401 et seq. (1997).

Individuals With Disabilities Education Improvement Act of 2004. Pub. L. No.108-446 (2004).

Individuals With Disabilities Education Improvement Act, 34 CFR Parts 300 and 301 (2006).

Jolivette, K., Kennedy, C., Puckett-Patterson, D., \& Houchins, D. E. (2008). Implementing a two-phase $24 / 7$ SW-PBS program in a residential facility for students with severe emotional and behavioral disorders and mental health needs. Manuscript submitted for publication.

Johns, B. H., Crowley, E. P., \& Guetzloe, E. (2002). Planning the IEP for students with emotional and behavioral disorders. Focus on Exceptional Children, 34(9), 1-12.

Kadish, T. E., Glaser, B. A., Calhoun, G. B., \& Risler, E. A. (1999). Counseling juvenile offenders: A program evaluation. Journal of Addictions and Offender Counseling, 19, 88-97.

Kartub, Taylor-Greene, S., March, E. R., \& Horner, R. H. (2000). Reducing hallway noise: A systems approach. Journal of Positive Behavior Interventions, 2, 179-182.

Kerr, M. M., \& Nelson, C. M. (2002). Strategies for addressing behavior problems in the classroom (4th ed.). Upper Saddle River, NJ: Merrill Prentice Hall.

Kleiner, B., Porch, R., \& Farris, E. (2002). Public alternative schools and programs for students at risk of education failure: 2000-01 (NCES 2002-004). Washington DC: U.S. Department of Education, National Center on Education Statistics.

Larson, K. A., \& Turner, D. (2002). Best practices for serving court involved youth with learning, attention, and behavioral disabilities. Monograph series on education, disability, and juvenile justice. Washington, DC: Center for Effective Collaboration and Practice and National Center on Education, Disability and Juvenile Justice.

Lassen, S. R., Steele, M. M., \& Sailor, W. (2006). The relationship of school-wide positive behavior support to academic achievement in an urban middle school. Psychology in the Schools, 43, 701-712.

Laupsin, C. J., Jolivette, K., \& Scott, T. M. (2005). Schoolwide systems of behavior support: Maximizing student success in schools. In R. B Rutherford Jr., M. M. Quinn, \& S. R. Mathur (Eds.), Handbook of research in emotional and behavioral disorders (pp. 487-501). New York: The Guilford Press.

Lehr, C. A., \& Lange, C. M. (2003). Alternative schools and the students they serve: Perceptions of state Directors of Special Education. Policy Research Brief. Minneapolis: University of Minnesota.

Lehr, C. A., Moreau, R. A., Lange, C. M., \& Lanners, E. J. (2004). Alternative schools: Findings from a national survey of the states (Research Report 2). Minneapolis: Alternative Schools Research Project, Institute on Community Integration, University of Minnesota.

Leichtman, M., Leichtman, M. L., Barber, C. B., \& Neese, D. T. (2001). Effectiveness of intensive short-term residential treatment with severely disturbed adolescents. American Journal of Orthopsychiatry, 71, 227-235.

Leone, P. E., Mayer, M. J., Malmgren, K., \& Meisel, S. M. (2000). School violence and disruption: Rhetoric, reality, and reasonable balance. Focus on Exceptional Children, 33(1), 1-20. 
Lewis, T. J., Hudson, S., Richter, M., \& Johnson, N. (2004). Scientifically supported practices in emotional and behavioral disorders: A proposed approach and brief review of current practices. Behavioral Disorders, 29, 247-259.

Lohrman, S., Forman, S., Martin, S., \& Palmieri, M. (2008). Understanding school personnel's resistance to adopting schoolwide positive behavior support at the universal level of intervention, Journal of Positive Behavior Intervention OnlineFirst, Retrieved September 3, 2008, from http://jpbi.sagepub.com

Luiselli, J. K., Putnam, R. F., Handler, M. W., \& Feinberg, A. B. (2005). Whole-school positive behaviour support: Effects on student discipline problems and academic performance. Educational Psychology, 25(2-3), 183-198.

Maag, J. W., \& Swearer, S. M. (2005). Cognitive-behavioral interventions for depression: Review and implications for school personnel. Behavioral Disorders, 30, 259-276.

McClelland, G. M., Elkington, K. S., Teplin, L. A., \& Abram, K. M. (2004). Multiple substance use disorders in juvenile detainees. Journal of the American Academy of Child and Adolescent Psychiatry, $43,1215-1224$.

McCloud, S. (2005, February). From chaos to consistency. Educational Leadership, 62, 46-49.

McIntosh, K., Chard, D. J., Boland, J. B., \& Horner, R. H. (2006). Demonstration of combined efforts in schoolwide academic and behavioral systems and incidence of reading and behavior challenges in early elementary grades. Journal of Positive Behavior Interventions, 8, 146-154.

McIntosh, K., Flannery, K. B., Sugai, G., Braun, D. H., \& Cochrane, K. L. (2008). Relationships between academics and problem behavior in the transition from middle school to high school. Journal of Positive Behavior Interventions OnlineFirst, 1-13. Retrieved August 20, 2008, from http://jpbi.sagepub.com

Metzler, C. W., Biglan, A., Rusby, J. C., \& Sprague, J. R. (2001). Evaluation of a comprehensive behavior management program to improve school-wide positive behavior support. Education \& Treatment of Children, 24(4), 448-479.

Mohr, W. K., \& Pumariega, A. J. (2004). Level systems: Inpatient programming whose time has passed. Journal of Child and Adolescent Psychiatric Nursing, 17, 113-125.

Nelson, C. M., \& Quinn, M. M. (2007, June). Implementing positive behavior support in programs for incarcerated juveniles. Presentation to the Central Massachusetts Department of Youth Services. Worchester, MA.

Nelson, C. M., Scott, T. M., Gagnon, J. C., Jollivette, K., \& Sprague, J. (2008). Positive behavior support in the juvenile justice system. Positive Behavioral Interventions and Supports Newsletter. Eugene, OR: Office of Special Education Programs Center on Positive Behavioral Interventions and Supports. Available at http://www. pbis.org/news/New/Newsletters/Newsletter4-3.aspx

Nelson, C. M., Sugai, G., \& Smith, C. R. (2005). Positive behavior support offered in juvenile corrections. Counterpoint, 1 (summer), 6-7.

Nelson, C. M., Sprague, J. R., Jolivette, K., Smith, C. R., \& Tobin, T. J. (in press). Positive behavior support in alternative education, community-based mental health and juvenile justice systems. In W. Sailor, G. Dunlap, and R. Horner (Eds.), Handbook of positive behavior support. New York: Springer.

Netzel, D. M., \& Eber, L. (2003). Shifting from reactive to proactive discipline in an urban school district: A change of focus through PBIS implementation. Journal of Positive Behavior Interventions, 5, 71-80.

Newcomer, P. L., Barenbaum, E., \& Pearson, N. (1995). Depression and anxiety in children and adolescents with learning disabilities, conduct disorders, and no disabilities. Journal of Emotional and Behavioral Disorders, 3, 27-40.

Nickerson, A. B., Brosof, A. M., \& Shapiro, V. B. (2004). Predicting positive outcomes for students with emotional disturbance. The California School Psychologist, 9, 39-49.

No Child Left Behind Act of 2001, Pub. L. No. 107-110, 115 Stat. 1425 (2002).

Noguera, P. A. (1995). Preventing and producing violence: A critical analysis of responses to school violence. Harvard Educational Review, 65(2), 189-212.

Office of Special Education Programs. (2004). School-wide positive behavior support: Implementers' blueprint and self-assessment. Retrieved October 30, 2008, from http://www.pbis.org/tools.htm

Oswald, K., Safran, S., \& Johanson, G. (2005). Preventing trouble: Making schools safer places using positive behavior supports. Education and Treatment of Children, 28, 265-278.

Penn, J. V., Esposito, C., Schaeffer, L. E., Fritz, G. K., \& Spirito, A. (2003). Suicide attempts and self-mutilative behavior in a juvenile correctional facility. Journal of the American Academy of Child and Adolescent Psychiatry, 42, 762-769.

The President's New Freedom Commission on Mental Health. (2003). Achieving the promise: Transforming mental health care in America. Retrieved April 19, 2006, from http://www.mentalhealthcommission.gov/reports/FinalReport/toc.html

Putnam, R. F., Horner, R. H., \& Algozzine, R. (2006). Academic achievement and the implementation of school-wide behavior support. Pos itive Behavioral Interventions and Supports Newsletter, 3(1), 1-8. University of Oregon: Technical Center on Positive Behavioral Interventions and Supports. Retrieved June 10, 2008, from http://www.pbis.org/news/New/Newsletters/Newsletter1.aspx

Quinn, M. M., \& Poirier, J. M. (2006). Study of effective alternative education programs: Final grant report. Washington, DC: American Institutes for Research.

Quinn, M. M., Rutherford, R. B., Leone, P. E., Osher, D. M., \& Poirier J. M. (2005). Youth with disabilities in juvenile corrections: A national survey. Exceptional Children, 71, 339-345.

Raywid, M. (1994). Alternative schools: State of the art. Educational Leadership, 52, 26-31.

Read, N. W., Quinn, M. M., \& Nelson, C. M. (2008). Implementing positive behavior interventions and supports in juvenile justice settings: What to expect and how to succeed. Unpublished manuscript.

Ryan, J. B., Reid, R., \& Ellis, C. (2008). A survey of special educator knowledge regarding psychotropic interventions for students with emotional and behavioral disorders. Remedial and Special Education, 29, 269-279.

Ryan, J. B., Reid, R., Gallagher, K., \& Ellis, C. (2008). Prevalence rates of psychotropic medications for students placed in residential facilities. Behavioral Disorders, 33, 99-107.

Sailor, W., Stowe, M. J., Turnbull, H. R. III, \& Kleinhammer-Tramill, J. (2007). A case for adding a social-behavioral standard to standardsbased education with schoolwide positive behavior support as its basis. Remedial and Special Education, 28, 366-376.

Scheuermann, B., \& Webber, J. (1996). Level systems: Problems and solutions. Beyond Behavior, 7(2), 12-17.

Scott, T. M. (2001). A schoolwide example of positive behavioral support. Journal of Positive Behavior Interventions, 3, 88-94.

Scott, T. M., \& Barrett, S. B. (2004). Using staff and student time engaged in disciplinary procedures to evaluate the impact of schoolwide PBS. Journal of Positive Behavior Interventions, 6, 21-27.

Scott, T. M., \& Eber. L. (2003). Functional assessment and wraparound as systemic school processes: School-wide, specialized, and intensive examples. Journal of Positive Behavior Interventions, 5, 131-143. 
Scott, T. M., Nelson, C. M., Liaupsin, C. J., Jolivette, K., Christle, C. A., \& Riney, M. (2002). Addressing the needs of at-risk and adjudicated youth through positive behavior support: Effective prevention practices. Education and Treatment of Children, 25, 532-551.

Shelton, D, (2000, Second Quarter). Health status of young offenders and their families. Journal of Nursing Scholarship, 173-178.

Sickmund, M. (2003). Juveniles in court. Juvenile offenders and victims: National report series. Washington, DC: U.S. Department of Justice, Office of Justice Programs, Office of Juvenile Justice and Delinquency Prevention.

Sidana, A. (2006). PBIS in juvenile justice settings. Washington DC: The National Evaluation and Technical Assistance Center for the Education of Children and Youth who are Neglected, Delinquent, and At Risk (NDTAC). Retrieved July 21, 2008, from http://www. neglecteddelinquent.org/nd/resources/spotlight/spotlight200601b .asp

Skowyra, K. R, \& Cocozza, J. J. (2006). Blueprint for change: A comprehensive model for the identification and treatment of youth with mental health needs in contact with the juvenile justice system. Delmar, NY: The National Center for Mental Health (NCMHJJ) and Policy Research Associates, Inc. Retrieved August 22, 2008, from www.ncmhjj.com/Bueprint/pdfs/Blueprint.pdf

Small, S., Reynolds, A., O'Connor, C., \& Cooney, S. (2005). What works, Wisconsin: What science tells us about cost-effective programs for juvenile delinquency prevention. Madison: University of Wisconsin.

Smith, S. W., \& Farrell, D. T. (1993). Level system use in special education: Classroom intervention with prima facie appeal. Behavioral Disorders, 18, 251-264.

Smith, S. W., Lochman, J. E., \& Daunic, A. P. (2005). Managing aggression using cognitive-behavioral interventions: State of the practice and future directions. Behavioral Disorders, 30, 227-240.

Snell, L. (2005, January). School violence and No Child Left Behind: Best practices to keep kids safe. Los Angeles CA: The Reason Foundation. Retrieved January 15, 2008 from www.reason.org/ps330.pdf

Snyder, H. N. (2005, August). Juvenile arrests 2003. Juvenile Justice Bulletin. Washington DC: U.S. Department of Justice, Office of Justice Programs, Office of Juvenile Justice and Delinquency Prevention.

Snyder, H. N., \& Sickmund, M. (2006). Juvenile offenders and victims: 2006 national report. Washington, DC: U.S. Department of Justice, Office of Justice Programs, Office of Juvenile Justice and Delinquency Prevention.

Sprague, J. R., \& Horner, R. H. (in press). School-wide positive behavior supports. In S. R. Jimerson \& M. J. Furlong (Eds.), The handbook of school violence and school safety: From research to practice. New Jersey: Erlbaum.

Stizek, G. A., Pittsonberger, J. L., Riordan, K. E., Lyter, D. M., \& Orlofsky, G. F. (2007). Characteristics of schools, districts, teachers, principals, and school libraries in the United States 2003-2004: School and staffing survey (NCES 2006-313 Revised). U.S. Department of Education, National Center for Education Statistics. Washington, DC: U.S. Government Printing Office.

Stroul, B. A., \& Freidman, R. (1986). A system of care for severely emotionally disturbed children and youth. Washington, DC: Child and Adolescent Service System Program Technical Assistance Center.

Sugai, G. \& Horner, R. H. (2005). Is school-wide positive behavior support an evidence-based practice? National Technical Assistance Center for Positive Behavior Interventions and Supports. Retrieved October 28, 2008, from http://www.pbis.org/files/ 101007evidencebase4pbs.pdf
Swarts, L. (2004). Alternative education accountability: Kentucky's approach. Impact 16(3), 21-22.

Teplin, L. A., Abram, K. M., McClelland, G. M., Dulcan, M. K., \& Mericle, A. A. (2002). Psychiatric disorders in youth in juvenile detention. Archives of General Psychiatry, 59, 1133-1143.

Todd, A. W., Lewis-Palmer, T., Horner, R. H., Sugai, G., Sampson, N. K., \& Phillips, D. (2003). School-wide evaluation tool implementation manual. Eugene: University of Oregon.

Trout, A. L., Linemann, T. O., Reid, R., \& Epstein, M. H. (2007). A review of non-medication interventions to improve the academic performance of children and youth with ADHD. Remedial and Special Education, 28, 207-226.

Turnbull, A., Edmonson, H., Griggs, P., Wickham, D., Sailor, W., Freeman, R., et al. (2002). A blueprint for schoolwide positive behavior support: Implementation of three components. Exceptional Children, 68(3), 377-402.

Underwood, L. A., Talbott, L. B., Mosholder, E., \& Von Dresner, K. S. (2008). Methodological concerns of residential treatment and recidivism for juvenile offenders with disruptive behavioral disorders. Journal of Behavior Analysis of Offender and Victim Treatment and Prevention, 1, 222-236.

U.S. Department of Education. (2002). Twenty-fourth annual report to congress on the implementation of the Individuals with Disabilities Education Act. Jessup, MD: Education Publications Center.

U.S. Department of Education. (2007). Twenty-seventh annual (2005) report to congress on the implementation of the Individuals with Disabilities Education Act, vol. 2. Washington, DC: Author.

U.S. Department of Health and Human Services. (1999). Mental health: A report of the Surgeon General. Washington, DC: Author.

Van Acker, R. (2007). Antisocial, aggressive, and violent behavior in children and adolescents within alternative education settings: Prevention and intervention. Preventing School Failure, 51(2), 5-12.

VanDenBerg, J. \& Grealish, M. (1996). Individualized services and supports through the wraparound process: Philosophy and procedures. Journal of Child and Family Studies 5, 7-21.

VanderVan, K. (1995). "Point and level systems": Another way to fail children and youth. Child \& Youth Care Forum, 24, 345-367.

Wagner, M., Cameto, R., \& Guzman, A. (2003). Who are secondary students in special education today? NLTS2 Data Brief, 2(1), 1-4.

Wald, J., \& Losen, D. J. (2003). Defining and redirecting a school to prison pipeline. New Directions for Youth Development, 99, 9-15.

Walker, B., Cheney, D., Stage, S., \& Blum, C. (2005). Schoolwide screening and positive behavior supports: Identifying and supporting students at risk for school failure. Journal of Positive Behavior Interventions, 7, 194-204.

Yell, M. L. \& Rozalski, M. E. (2000). Searching for safe schools: Legal issues in the prevention of school violence. Journal of Emotional and Behavioral Disorders, 8, 187-196.

Whitted, K. S., \& Dupper, D. R. (2005). Best practices for preventing or reducing bullying in schools. Children and Schools, 27, 167-175. 